\title{
LA-UR-00= 483
}

Title:

FEMTOSECOND PULSE DELIVERY THROUGH SINGLE-MODE OPTICAL FIBER WITH ADAPTIVE PULSE SHAPING

Author(s):

Fiorenzo G. Omenetto, Antionette J. Taylor, MST-10, LANL Mark D. Moores, David H. Reitze, University of Florida Benjamin P. Luce, T-7, LANL

Submitted to:

To be presented at Conference of Lasers and

Electro-Optics 01

Baltimore

May 6-11, 2001

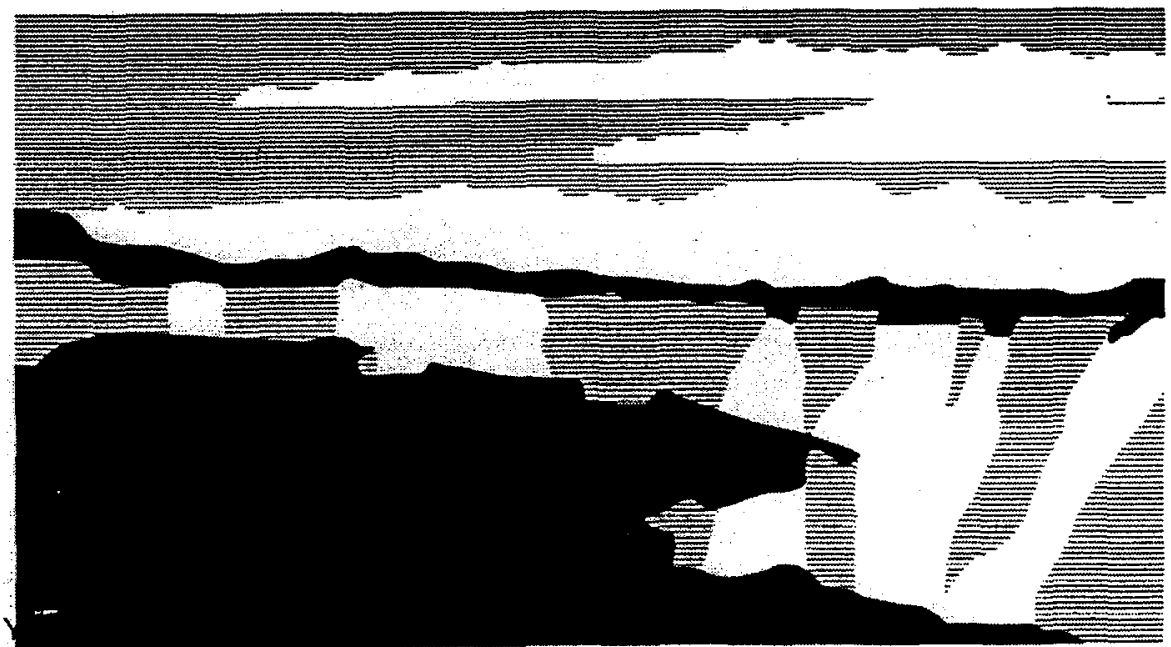

Los Alamos National Laboratory, an affirmative action/equal opportunity employer, is operated by the University of California for the U.S. Department of Energy under contract W-7405-ENG-36. By acceptance of this article, the publisher recognizes that the U.S. Govemment retains a nonexclusive, royalty-free Icense to publish or reproduce the published form of this contribution, or to allow others to do so, for U.S. Govemment purposes. The Los Alamos National Laboratory requests that the publisher identify this article as work performed under the auspices of the U.S. Department of Energy. 


\section{DISCLAIMER}

This report was prepared as an account of work sponsored by an agency of the United States Government. Neither the United States Government nor any agency thereof, nor any of their employees, make any warranty, express or implied, or assumes any legal liability or responsibility for the accuracy, completeness, or usefuiness of any information, apparatus, product, or process disclosed, or represents that its use would not infringe privately owned rights. Reference herein to any specific commercial product, process, or service by trade name, trademark, manufacturer, or otherwise does not necessarily constitute or imply its endorsement, recommendation, or favoring by the United States Government or any agency thereof. The views and opinions of authors expressed herein do not necessarily state or reflect those of the United States Government or any agency thereof. 


\section{DISCLAIMER}

Portions of this document may be illegible in electronic image products. Images are produced from the best available original document. 


\title{
Femtosecond pulse delivery through single-mode optical fiber with adaptive pulse shaping
}

\author{
Fiorenzo G. Omenetto ${ }^{1}$, Mark D. Moores ${ }^{3}$, Benjamin P. Luce ${ }^{2}$, David H. Reitze ${ }^{3}$ and Antoinette J. Taylor ${ }^{1}$ \\ (1) Materials Science and Technology Division, MST-10, MS K764, \\ (2) Theoretical Division, T-7, \\ Los Alamos, NM 87545 \\ (3) Dept. of Physics, University of Florida, Gainesville, Fla. 32611
}

\begin{abstract}
Adaptive control is used to defeat nonlinear effects that severely distort ultrafast pulses during propagation through optical fibers.

(C)2000 Optical Society of America

OCIS codes: (320.7100)Ultrafast optics, (060.7140), (320.7140), Ultrafast processes in fibers, (320.5550) Pulses
\end{abstract}

Nonlinear effects present fundamental obstacles for the propagation of femtosecond pulses of detectable energy in single-mode optical fibers, inducing severe distortion even after a very short propagation distance. These effects are extremely hard to defeat or even predict. Adaptive pulse shaping can overcome these limitations by synthesizing pulses that are self-correcting for higher order nonlinear effects when launched in the fiber.

In the experiment presented here, an initially unshaped pulse of power $P=25 \mathrm{~mW}$ and $\tau=204 \mathrm{fs}$ is coupled into a a 10 meter single-mode (Corning SMF-28) optical fiber segment. For the pulse and fiber parameters employed, the dispersion length $L_{D}=\tau_{0} / \beta_{2} \mid$ is equal to $2 \mathrm{~m}$, whereas the nonlinear length $L_{N L}=1 /\left(\gamma P_{0}\right)$ is $\sim 20 \mathrm{~cm}$, where $\tau_{0}$ and $P_{0}$ are the initial pulsewidth and peak power, $\beta_{2}$ is the group velocity dispersion parameter (in $\mathrm{ps}^{2} / \mathrm{Km}$ ) and $\gamma$ is the nonlinearity coefficient $\left(\mathrm{n}_{2} \omega_{0} / \mathrm{CA}_{\mathrm{eff}}\right)$. The ratio $\mathrm{L}_{\mathrm{D}} / \mathrm{L}_{\mathrm{NL}}=10$ indicates that the pulse distortion is governed mostly by nonlinear effects. The pulse resulting from the unshaped pulse propagation is temporally broadened to $\tau=352$ fs and has become distorted (fig. 1). Higher-order nonlinear effects come into play in this case, and are apparent both in the asymmetric broadening of the pulse and in the structure present in the wings of the pulse.


Fig. 1 Profile of the output of an unshaped $204 \mathrm{fs}$ pulse after propagation through 10 meters of fiber. The phase function is also shown.

The recovered temporal phase function, obtained by deconvolution of a FROG trace (1-3), reveals the presence of appreciable higher order (cubic, quartic) components. An adaptive control feedback loop (illustrated in figure 2) that applies a phase-only modulation on the pulse to be launched in the fiber is then applied. After the loop has converged, the output pulse resulting from the launch of the optimized shaped input pulse has a time duration of $213 \mathrm{fs}$. The comparison of the output resulting from the unshaped and shaped pulse propagation on a logarithmic 
scale is illustrated in fig. 3. For the output pulse that results from the propagation of the unoptimized input, the structure of the pulse is substantial throughout its temporal profile.

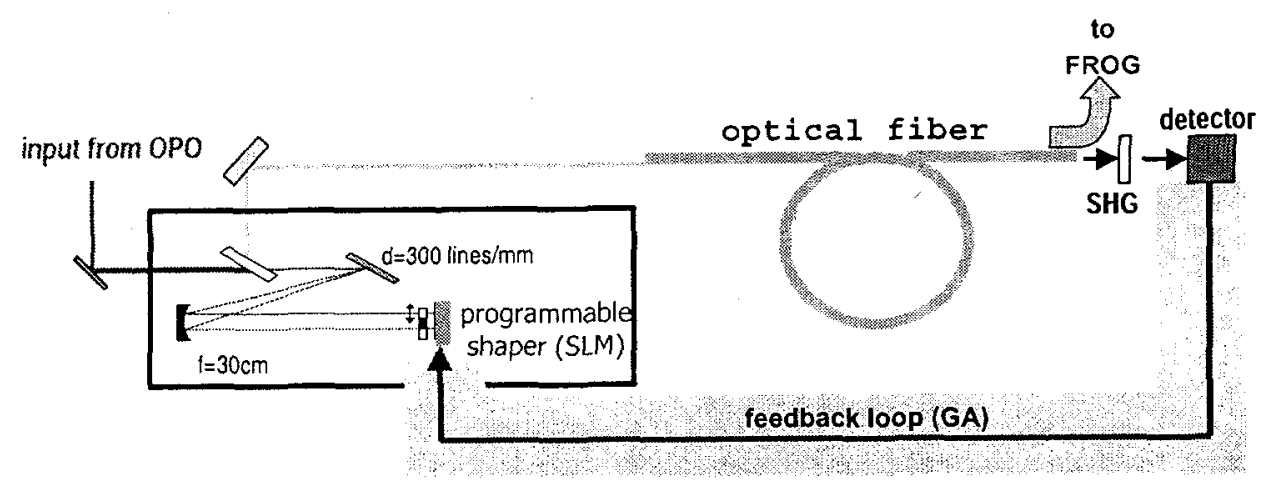

Fig. 2 Schematic of the adaptive pulse shaper for ultrashort pulse propagation in fibers. Pulses at $\lambda=1.55 \mu \mathrm{m}$ are sent to a pulse shaper implemented as a folded zero-dispersion stretcher with a phase-only spatial light modulator (SLM) located in the Fourier plane, and then sent to a 10-meter link of conventional single-mode optical fiber (Coming SMF-28). The output from the fiber is then sent to a $0.5 \mathrm{~mm}$ thick BBO-crystal that provides the SH control signal for the genetic algorithm.

The optimized output pulse reveals, in contrast, no detectable wing structure over the same range, and a pulse shape approaching that of the original unshaped input pulse, especially on the leading edge. The peak intensity of the optimized output exceeds that of the unoptimized output pulse by a factor of two. By analyzing the optimized shaped input pulse temporal phase function and comparing it to the unshaped pulse, the nature and relative effect of the nonlinearities can be determined. Specifically, by fitting the recovered temporal phase function, a strong compensation effect can be detected on the cubic and quartic phase terms, identifying these nonlinearities as the dominant contributions to the distortion of the propagating pulse.

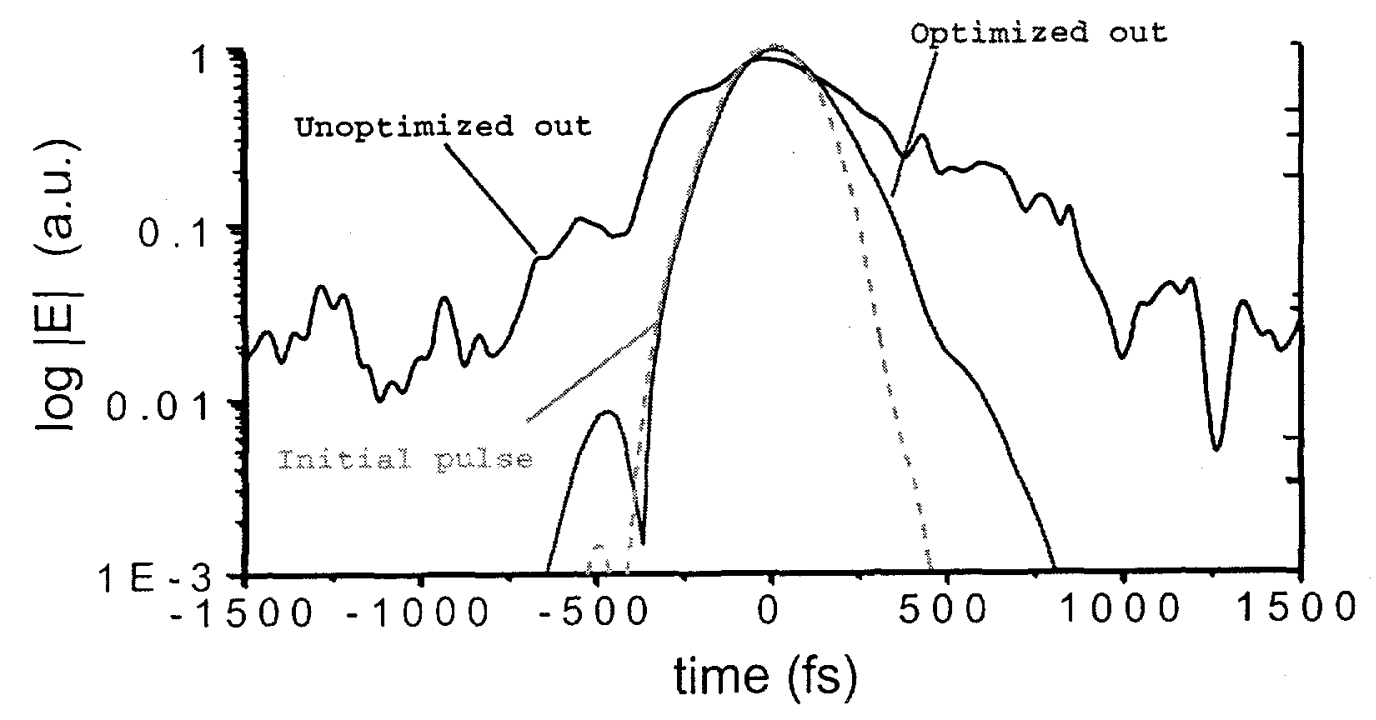

Fig. 3 Comparison of the initial unshaped pulse (dashed line), output from the unshaped pulse and output from the optimally shaped pulse propagation plotted on a logarithmic scale to the extent of the dynamic range of the measurement. The effect of optimization is remarkable, especially in the wings of the pulse. 
These results demonstrate the feasibility of fiber delivery of energetic ultrashort pulses defeating the nonlinear propagation effects by appropriate preshaping of the input pulse through linear filtering combined with adaptive control. These results are of fundamental importance in both the applied and basic realms where delivery of energetic ultrashort pulses is needed and the successful application of this technique will impact many fields, such as telecommunications, nonlinear imaging, optical coherence tomography or materials processing, to name a few .

\section{References}

1. F. G. Omenetto, B. Luce, D. Yarotsky, and A. J. Taylor, Opt. Lett., 24, 1392 (1999)

2. F. G. Omenetto, J. W. Nicholson and A. J. Taylor, Opt. Lett. 24, 1780, 1999

3. R. Trebino, K. W. DeLong, D. Fittinghoff, J. Sweetster, M. A. Krumbugel and D. Kane, Rev. Sci. Instr., 68, 3277 (1977) 